\title{
Vasodilator Effects of Flunarizine on Retinal Blood Vessels in Anesthetized Rats
}

\author{
Masahiro Noguchi, Asami Mori, Kenji Sakamoto, Tsutomu Nakahara, * and Kunio IshiI \\ Department of Molecular Pharmacology, Kitasato University School of Pharmaceutical Sciences; 5-9-1 Shirokane, \\ Minato-ku, Tokyo 108-8641, Japan. \\ Received August 21, 2009; accepted September 11, 2009; published online October 2, 2009
}

\begin{abstract}
The aim of this study was to investigate the effects of intravenous administration of flunarizine on the diameter of retinal blood vessels and blood pressure in anesthetized rats and to compare the effects of this antagonist with those of nicardipine and nifedipine. Retinal vascular images were captured with a fundus camera system for small animals and the diameter of retinal blood vessels contained in the images was measured using imageprocessing softwares on a personal computer. Blood pressure was continuously measured. Flunarizine [1$30 \mu \mathrm{g} / \mathrm{kg}$, intravenously (i.v.)] dose-dependently increased the diameter of retinal blood vessels without significantly changing systemic blood pressure. Nicardipine $(1-30 \mu \mathrm{g} / \mathrm{kg}$, i.v.) increased the retinal blood vessel diameter but decreased blood pressure in a dose-dependent manner. Nifedipine $(10-100 \mu \mathrm{g} / \mathrm{kg}$, i.v.) failed to dilate the retinal blood vessels, although it produced comparable depressor responses as those to nicardipine. These results suggest that flunarizine selectively acts on the retinal blood vessels rather than on the peripheral resistance vessels. Flunarizine could therefore be considered as a candidate for therapeutic drugs to treat diseases associated with disorders of retinal circulation without severe cardiovascular side-effects.
\end{abstract}

Key words blood pressure; calcium channel antagonist; flunarizine; retinal blood vessel; vasodilation

It has been proposed that the impairment of retinal circulation contributes to the pathogenesis of ocular diseases, such as diabetic retinopathy ${ }^{1,2)}$ and glaucoma. ${ }^{3,4)}$ Therefore, agents that improve the retinal circulation would become therapeutic candidates for slowing the progression of these diseases.

Several L-type $\mathrm{Ca}^{2+}$ channel antagonists have been shown to improve the retinal blood flow, ${ }^{5,6)}$ however, these drugs generally produce a marked reduction in systemic blood pressure when administered systemically. A topical administration to eyes is one way to limit the occurrence of systemic cardiovascular side-effects, such as hypotension and reflex tachycardia, but an ideal drug selectively acts on retinal blood vessels rather than on systemic resistance vessels.

Flunarizine is a non-selective $\mathrm{Ca}^{2+}$ channel antagonist that dilates the cerebral blood vessels more than the systemic blood vessels. ${ }^{78}$ B) Because the retinal vasculature anatomically and functionally resembles the cerebral vasculature, ${ }^{9,10)}$ flunarizine may produce a potent vasodilator effect on retinal blood vessels. Indeed, flunarizine was shown to improve the blood flow to the optic nerve head in patients with lowtension glaucoma. ${ }^{11)}$ However, it remains to be elucidated whether flunarizine exerts the vasodilatory effects on retinal blood vessels without affecting systemic blood pressure even when administered systemically.

The purpose of this study, therefore, was to examine the effects of intravenously administered flunarizine on the diameter of retinal blood vessels and blood pressure in anesthetized rats. We also compared the effects of flunarizine with those of nicardipine and nifedipine.

\section{MATERIALS AND METHODS}

Experimental Procedures The present study was conducted in accordance with the Guidelines for the Care and Use of Laboratory Animals adopted by the Committee on the Care and Use of Laboratory Animals of Kitasato University.

Sixteen male Wistar rats weighing $250-300 \mathrm{~g}$ were main- tained in a room with constant temperature $\left(22 \pm 2^{\circ} \mathrm{C}\right)$, constant humidity $(55 \pm 5 \%)$, and 12 -h light/dark cycle and allowed free access to regular rat chow and tap water. The animals were divided into four groups of four rats each (flunarizine, nicardipine, nifedipine and vehicle groups).

The rats were anesthetized with an initial dose of urethane [600 mg/kg, intraperitoneal (i.p.)] and $\alpha$-chloralose $(60 \mathrm{mg} /$ $\mathrm{kg}$, i.p.). After disappearance of the corneal reflex, each animal was placed on a heating pad. A tracheotomy was performed and a catheter was inserted into the femoral vein for administration of drugs. The left femoral artery was cannulated for measurement of arterial pressure (AP), which was recorded on a thermal pen recorder (WT-645G, Nihon Kohden, Tokyo), via a pressure transducer (DX-360, Nihon Kohden) and a preamplifier (AP-610G, Nihon Kohden). Heart rate (HR) was measured with a cardiotachometer (AT-601G, Nihon Kohden) triggered by the blood pressure pulse. Systemic blood pressure and $\mathrm{HR}$ were digitized at $1 \mathrm{~Hz}$ using SCIENCE LINK II (Keisoku Giken, Utsunomiya) and stored on the hard disk of a personal computer (PowerBook 165C, Apple Japan, Tokyo) throughout the experimental period. Supplemental doses of anesthetics were given as necessary via the femoral vein.

After hemodynamic parameters reached stable levels (approximately $40 \mathrm{~min}$ after administration of anesthetics), intravenous injections of flunarizine $(1,3,10,30 \mu \mathrm{g} / \mathrm{kg})$ (Sigma-Aldrich, St. Louis, MO, U.S.A.), nicardipine (SigmaAldrich) $(1,3,10,30 \mu \mathrm{g} / \mathrm{kg})$, nifedipine (Sigma-Aldrich) $(10,30,100 \mu \mathrm{g} / \mathrm{kg})$ or the vehicle (polyethylene glycol 400 : ethanol: water $=3: 1: 1$ ) were given at 10 min-intervals, because in preliminary studies we found that each drug response reached a plateau within 10 min after injection, and the length of an examination period should be short for the recording of retinal vascular images under the same conditions.

Measurement of Retinal Blood Vessel Diameter The diameter of retinal blood vessels was measured as described 
previously. ${ }^{12)}$ Briefly, the pupils were dilated with one drop of $1 \%$ atropine sulfate (Nihon Tenganyaku Institute, Nagoya). To protect the eye, $0.3 \%$ sodium hyalurate (Santen Pharmaceutical, Osaka) was dropped onto the cornea. The optic disc was centered and focused in the field of view. Sodium fluorescein [10\% solution, $0.8 \mathrm{ml} / \mathrm{kg}$, intravenously (i.v.)] and brilliant blue $6 \mathrm{~B}(5 \%$ solution, $0.8 \mathrm{ml} / \mathrm{kg}$, i.v. $)$ were injected into the femoral vein to enhance vessel contrast. Real-time retinal vascular images were obtained using a fundus camera system for small animals (Model VMS-170, Scalar, Tokyo), displayed on a 14-inch display (KV-14GP3, Sony, Tokyo), and recorded on a digital videotape with a digital video tape recorder (WV-D10000, Sony, Tokyo) for off-line processing. The vascular images were captured from each recorded movie using the image capture system (Photo DV, 1.1.1., Radius Tokyo, Tokyo) on a Power Macintosh G3-266DT (Apple Japan, Tokyo). The full-color (RGB) images were processed using image processing software (Photoshop 5, Adobe, Systems Inc., San Jose, CA, U.S.A.). We chose the green channel image, which provided the greatest contrast among three individual color channels, for further processing. After intensifying the contrast of the retinal blood vessels, the region $(80 \times 160 \mu \mathrm{m})$ containing a retinal arteriole or a retinal venule in the fundus image $(2560 \times 3413 \mu \mathrm{m})$ was selected. Blood vessels were distinguished from the background by determining a certain threshold value for each image. The diameter of the vessel was calculated by dividing the vessel's area by its length in the selected area (NIH image 1.6.2., National Institutes of Health, Bethesda, MD, U.S.A.). The diameter of blood vessel in the same region was measured throughout the experiment.

Data Analyses The diameter of the retinal blood vessel, mean arterial pressure, and heart rate were expressed as percentages of the baseline values just before the injection of each $\mathrm{Ca}^{2+}$ channel antagonist or the vehicle. Data were analyzed by one-way ANOVA followed by the Scheffé post hoc test. A $p$ value of less than 0.05 was considered to represent a statistically significant difference. All values are presented as mean \pm S.E.M.

\section{RESULTS}

Baseline values of retinal arteriolar diameter, retinal venular diameter, mean arterial pressure (MAP) and HR of anesthetized rats used in this study are summarized in Table 1. There were no significant differences in baseline values among the groups.

Figure 1 shows the representative fundus images captured at baseline condition and $10 \mathrm{~min}$ after injection of flunarizine (30 $\mu \mathrm{g} / \mathrm{kg}$, i.v.). Flunarizine increased the diameter of retinal blood vessels; the data are summarized in Fig. 2. As shown in Fig. 2A, injections of the vehicle did not elicit significant responses, whereas flunarizine increased the diameter of retinal blood vessels in a dose-dependent manner without affecting MAP (Fig. 2B). On the other hand, nicardipine dosedependently increased the retinal blood vessel diameter but decreased MAP (Fig. 2C). Nifedipine exhibited no significant effect on retinal blood vessels, despite the comparable depressor responses with nicardipine (decreases in MAP, $30 \mu \mathrm{g} / \mathrm{kg}$ of nifedipine, $15.2 \pm 3.2 \%, n=4 v s .30 \mu \mathrm{g} / \mathrm{kg}$ of nicardipine, $16.3 \pm 4.2 \%, n=4)$ (Fig. 2D). The doses of $\mathrm{Ca}^{2+}$
Table 1. Baseline Values of Retinal Arteriolar Diameter (AD), Retinal Venular Diameter (VD), Mean Arterial Pressure (MAP) and Heart Rate (HR) of Anesthetized Rats

\begin{tabular}{lccrc}
\hline \hline \multicolumn{1}{c}{ Group } & $\begin{array}{c}\mathrm{AD} \\
(\mu \mathrm{m})\end{array}$ & $\begin{array}{c}\mathrm{VD} \\
(\mu \mathrm{m})\end{array}$ & $\begin{array}{c}\mathrm{MAP} \\
(\mathrm{mmHg})\end{array}$ & $\begin{array}{r}\text { HR } \\
(\text { beats/min })\end{array}$ \\
\hline Vehicle $(n=4)$ & $51.7 \pm 2.4$ & $65.5 \pm 1.8$ & $97 \pm 6$ & $431 \pm 10$ \\
Flunarizine $(n=4)$ & $52.6 \pm 1.4$ & $72.5 \pm 1.4$ & $98 \pm 4$ & $443 \pm 6$ \\
Nicardipine $(n=4)$ & $50.3 \pm 1.2$ & $68.3 \pm 1.4$ & $100 \pm 5$ & $456 \pm 15$ \\
Nifedipine $(n=4)$ & $55.1 \pm 1.6$ & $72.5 \pm 2.0$ & $97 \pm 5$ & $469 \pm 8$ \\
\end{tabular}

Values are mean \pm S.E.M.

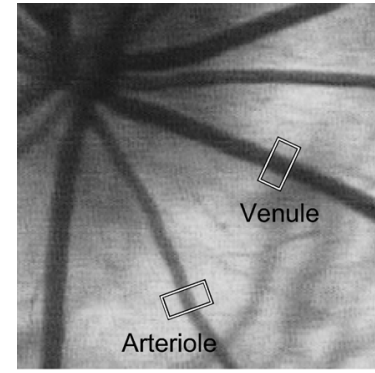

Before

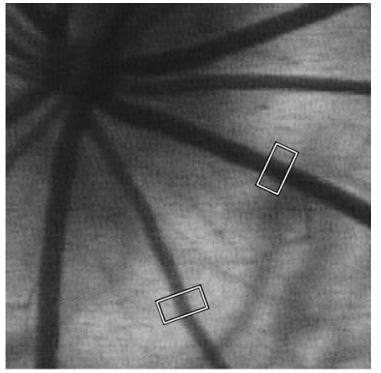

Flunarizine
Fig. 1. Representative Fundus Images Captured at Baseline Condition and $10 \mathrm{~min}$ after Injection of Flunarizine $(30 \mu \mathrm{g} / \mathrm{kg}$, i.v.) in an Anesthetized Rat

Flunarizine dilated retinal blood vessels. In this case, the diameters of blood vessels in the selected regions were measured. The increases in arteriolar diameter and venular diameter were $11.7 \%$ and $5.5 \%$, respectively.

channel antagonists tested in this study had no significant effect on HR (data not shown).

\section{DISCUSSION}

Previous studies have shown that a number of $\mathrm{Ca}^{2+}$ channel antagonists had beneficial effects on retinal ischemic models. ${ }^{13-15)}$ Two mechanisms have been proposed to account for the effects, one is a direct protective effect on retinal neurons and the other is an improvement of blood supply to retinal neurons. ${ }^{15-18)}$ The relative importance of the two mechanisms in the beneficial effects is unclear; however, the drug that exhibits protective effects through both mechanisms without affecting systemic hemodynamics may be ideal. The present study demonstrates that flunarizine produces the vasodilation of retinal blood vessels without significantly affecting systemic blood pressure in anesthetized rats. Nicardipine also dilated the retinal blood vessels, whereas it decreased systemic blood pressure significantly. On the other hand, nifedipine failed to exhibit the vasodilator effect on retinal blood vessels, despite the marked depressor responses. These results suggest that flunarizine may be useful to improve the impaired retinal circulation without significant systemic cardiovascular side-effects.

Our intent in this study was to compare vasodilator effects on retinal blood vessels with those on peripheral resistance vessels by measuring changes in diameter of retinal blood vessels and systemic blood pressure induced by intravenous injections of $\mathrm{Ca}^{2+}$ channel antagonists. However, the results need to be interpreted with caution as discussed below. First, several $\mathrm{Ca}^{2+}$ channel antagonists have been demonstrated to lower intraocular pressure (IOP) ${ }^{18-20)}$ and the blockade of $\mathrm{Ca}^{2+}$ channels in neuronal cells could influence the release of 

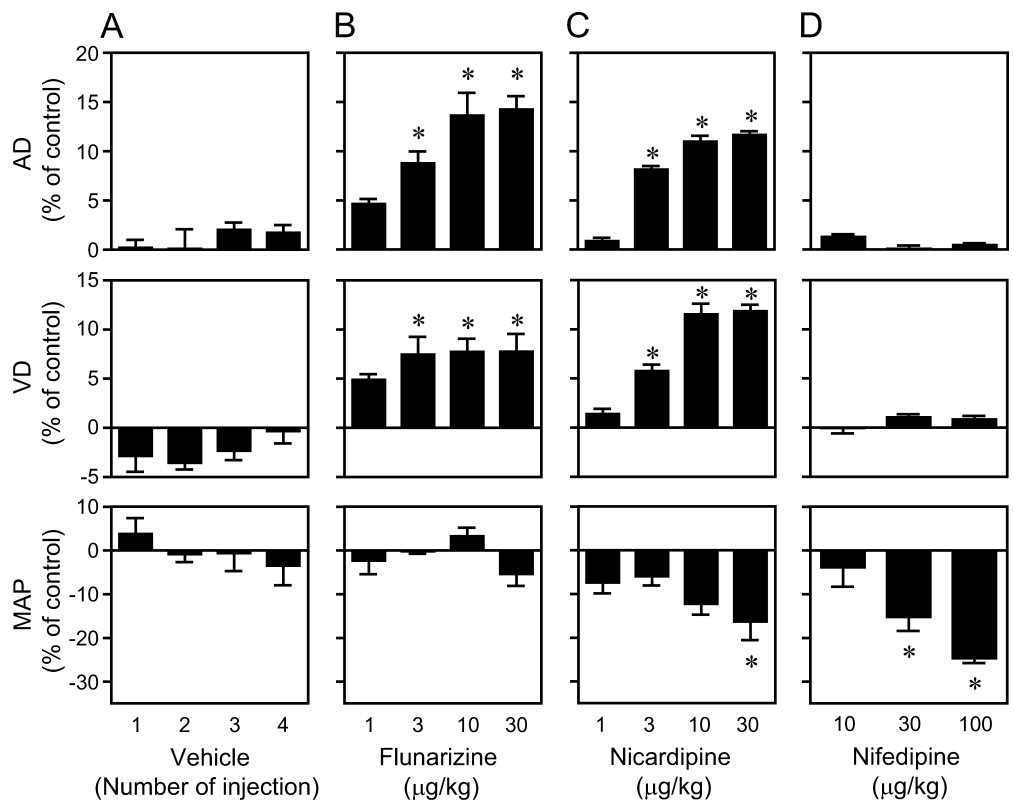

Fig. 2. Effects of Flunarizine, Nicardipine and Nifedipine on Retinal Arteriolar Diameter (AD), Retinal Venular Diameter (VD), Mean Arterial Pressure (MAP) and Heart Rate (HR) in Anesthetized Rats

Each $\mathrm{Ca}^{2+}$ channel antagonist was injected into the femoral vein at 10 min-intervals. The vehicle was administered in a similar fashion. Data are expressed as percentage of the baseline value measured just before the injection of the $\mathrm{Ca}^{2+}$ channel antagonist. Each column with a vertical bar represents mean \pm S.E.M. of 4 animals. $* p<0.05$ vs. corresponding baseline values.

neurotransmitters..$^{21,22)}$ These actions, in addition to the direct actions on retinal blood vessels, may affect the diameter of retinal blood vessels. Second, it is well known that a change in the retinal arteriolar pressure leads to a compensatory change in the vascular diameter, ensuring a constant capillary perfusion (i.e., pressure autoregulation). ${ }^{23,24)}$ Thus, changes in systemic blood pressure might alter the diameter of retinal blood vessels. However, it is unlikely that the autoregulatory mechanisms alone explain the vasodilator responses of retinal arterioles observed in this study, because flunarizine increased the diameter of retinal blood vessels without changing systemic blood pressure, and nifedipine failed to increase the diameter of retinal blood vessels, despite marked depressor responses.

Nicardipine and nifedipine, unlike flunarizine, markedly decreased systemic blood pressure. The differences may be due to the differential ion channel selectivity of the drugs. Both nicardipine and nifedipine selectively block L-type $\mathrm{Ca}^{2+}$ channels, whereas flunarizine non-selectively blocks Land T-type $\mathrm{Ca}^{2+}$ channels and is also an effective $\mathrm{Na}^{+}$channel antagonist. ${ }^{25}$ Flunarizine-sensitive ion channels may be more important in regulation of retinal circulation than in that of systemic circulation.

Previous studies have shown that flunarizine dilates the cerebral blood vessels more than the systemic blood vessels. ${ }^{7,8)}$ Several similarities between retinal and cerebral vasculature have been recognized. ${ }^{9,10)}$ For example, 1) retinal endothelial cells form the blood-retinal barrier with a similar function as the blood-brain barrier, ${ }^{26,27)}$ and 2) an autoregulatory mechanism for blood flow is present in the retinal and optic nerve head circulation as in the cerebral circulation. ${ }^{27,28)}$ In addition to these similarities, our present study may indicate that the $\mathrm{Ca}^{2+}$ channels which are involved in regulating retinal vasculature tone resemble those in regulating cerebral vasculature tone.
The reason why nicardipine and nifedipine exhibited differential effects on retinal blood vessels is unclear at present. However, the difference in vasodilator actions on cerebral blood vessels between these two antagonists was reported. ${ }^{29)}$ Therefore, this finding also supports the similarities of mechanisms that are involved in regulation of retinal and cerebral vascular tone.

In conclusion, we found that flunarizine has a greater effect on retinal blood vessels than on systemic resistance vessels and, therefore, it may be an effective drug that improves the retinal circulation without producing the systemic sideeffects (e.g., hypotension) generally seen with other $\mathrm{Ca}^{2+}$ channel antagonists.

Acknowledgments This study was supported in part by Grants-in-Aid for Scientific Research from the Ministry of Education, Culture, Sports, Science and Technology of Japan (Nos. 10672051 and 12672116) and the Suzuken Memorial Foundation.

\section{REFERENCES}

1) Schmetterer L., Wolzt M., Diabetologia, 42, 387-405 (1999).

2) De La Cruz J. P., González-Correa J. A., Guerrero A., de la Cuesta F. S., Diabetes Metab. Res. Rev., 20, 91-113 (2004).

3) Flammer J., Orgül S., Costa V. P., Orzalesi N., Krieglstein G. K., Serra L. M., Renard J. P., Stefánsson E., Prog. Retin. Eye Res., 21, 359-393 (2002).

4) Grieshaber M. C., Flammer J., Curr. Opin. Ophthalmol., 16, 79-83 (2005).

5) Netland P. A., Feke G. T., Konno S., Goger D. G., Fujio N., J. Glaucoma, 5, 200-206 (1996).

6) Tamaki Y., Araie M., Tomita K., Tomidokoro A., Jpn. J. Ophthalmol., 40, 202-211 (1996).

7) Bian K., Toda N., Jpn. J. Pharmacol., 49, 83-94 (1989).

8) Zumkeller M., Heissler H. E., Dietz H., Neurosurg. Rev., 20, 259-268 (1997).

9) Delaey C., Van De Voorde J., Ophthalmic Res., 32, 249-256 (2000). 
10) Patton N., Aslam T., Macgillivray T., Pattie A., Deary I. J., Dhillon B., J. Anat., 206, 319-348 (2005).

11) Cellini M., Possati G. L., Caramazza N., Profazio V., Caramazza R., Acta Ophthalmol. Scand. Suppl., 224, 57-58 (1997).

12) Noguchi M., Mori A., Sakamoto K., Nakahara T., Ishii K., Biol. Pharm. Bull., 32, 1924-1927 (2009).

13) Crosson C. E., Willis J. A., Potter D. E., J. Ocul. Pharmacol., 6, $293-$ 299 (1990).

14) Takahashi K., Lam T. T., Edward D. P., Buchi E. R., Tso M. O., Arch. Ophthalmol., 110, 862-870 (1992).

15) Toriu N., Akaike A., Yasuyoshi H., Zhang S., Kashii S., Honda Y., Shimazawa M., Hara H., Exp. Eye Res., 70, 475- 484 (2000).

16) Edward D. P., Lam T. T., Shahinfar S., Li J., Tso M. O., Arch. Ophthalmol., 109, 554-562 (1991).

17) Eschweiler G. W., Bähr M., J. Neurol. Sci., 116, 34-40 (1993).

18) Osborne N. N., Wood J. P., Cupido A., Melena J., Chidlow G., Invest. Ophthalmol. Vis. Sci., 43, 1456-1464 (2002).

19) Siegner S. W., Netland P. A., Schroeder A., Erickson K. A., J. Glauсота, 9, 334-339 (2000).
20) Wang R. F., Gagliuso D. J., Podos S. M., J. Glaucoma, 17, 73-78 (2008).

21) Tamura N., Yokotani K., Okuma Y., Okada M., Ueno H., Osumi Y., Brain Res., 676, 363-370 (1995).

22) Pan Z. H., Hu H. J., Perring P., Andrade R., Neuron, 32, 89-98 (2001).

23) Riva C. E., Sinclair S. H., Grunwald J. E., Invest. Ophthalmol. Vis. Sci., 21, 34-38 (1981).

24) Robinson F., Riva C. E., Grunwald J. E., Petrig B. L., Sinclair S. H., Invest. Ophthalmol. Vis. Sci., 27, 722-726 (1986).

25) Grima M., Freyss-Beguin M., Millanvoye-Van Brussel E., Decker N., Schwartz J., Eur. J. Pharmacol., 138, 1-8 (1987).

26) Bill A., Physiol. Rev., 55, 383- 417 (1975).

27) Bill A., Nilsson S. F., J. Cardiovasc. Pharmacol., 7 (Suppl. 3), S96S102 (1985).

28) Harris A., Ciulla T. A., Chung H. S., Martin B., Arch. Ophthalmol., 116, 1491-1495 (1998).

29) Kuriyama Y., Hashimoto H., Nagatsuka K., Sawada T., Omae T., J. Hypertens., 11 (Suppl.), S9-S12 (1993). 